\title{
AGE FEATURES OF BONE TISSUE DENSITY IN THE POSTERIOR AND INFERIOR WALLS OF THE FRONTAL SINUS
}

\author{
Gargin V.V., Lupyr A.V., Alekseeva V.V.,Yurevych N.O.
}

Kharkiv National Medical University, Ukraine

\begin{abstract}
Chronic rhinosinusitis is a significant social, medical and economical problem. Elderly patients are unique among all groups of patients. The purpose of our study was to determine physiological variability of frontal sinus in the posterior and inferior walls and to compare it with variability in purulent-polypous rhinosinusitis. Subjects and methods: The study involved SCT examination of 40 male patients: 10 tomograms of patients aged 30-40 and 10 of patients aged 75-85. The tomograms of patients without ENT diseases were used for the control group. The study group included tomograms of patients aged 30-40 and 75-85 with chronic rhinosinusitis. Results. An average bone density of the posterior and inferior walls of the frontal sinuses was calculated. The bone density of the group aged 30-40 was $191.5 \pm 11.6 \mathrm{Hu}$ in the inferior wall, $176.6 \pm 21 \mathrm{Hu}$ in the posterior and $169.1 \pm 16.8 \mathrm{Hu}$ and $164 \pm 21 \mathrm{Hu}$ in the group aged 75-85 according to the above order. The study showed pronounced changes in the bone density in purulent-polypous frontal sinusitis. In the group aged 30-40 it was as follows: $120.1 \pm 8.3 \mathrm{Hu}, 162.1 \pm 24 \mathrm{Hu}$ in the inferior wall and $101.4 \pm 6.95 \mathrm{Hu}$, 127.4.8 $\pm 15.4 \mathrm{Hu}$ in the posterior wall. Conclusions: It can be assumed that the decrease in the bone density is associated with age. And it is more severe in case of chronic frontal sinusitis.
\end{abstract}

Key words: Frontal sinus, CT, elderly, bone density.

\section{Introduction}

Chronic rhinosinusitis represents a significant social, medical and economic problem [1]. According to some reports, the incidence of this disease can be equal to diabetes and heart diseases [12] and accounts for $10.9 \%$ of the urban population in Europe and $12.5 \%$ of the United States population [5]. The course of chronic rhinosinusitis has distinct age-specific features, which also affect the methods of further treatment [7]. Elderly patients occupy a special place among all groups of patients. The incidence of complications of rhinosinusitis at this age is much greater than in younger patients, although clinical presentation of inflammatory diseases affecting the perineal sinuses is less severe due

Corresponding Author:

Tetyana Chaychenko, $\mathrm{MD}, \mathrm{PhD}$, Professor of Department of Pediatrics 1 and Neonatology of Kharkiv National

Medical University, Ukraine.

E-mail: tatyana.chaychenko@gmail.com to changes in the immune status, hormonal age changes, concomitant diseases, changes in behavior, namely predisposition to depressive states. The most severe intracranial and intraorbital complications are associated with frontal sinusitis [13]. Bone alteration is, in particular, one of the most significant links in the development of chronic rhinosinusitis in general and chronic frontal infections and is associated with demineralization, disappearance of trabecula, cortical destruction and focal sclerosis. These changes may correlate with the severity of the disease [2]. There are ways to predict the probability of complications by bone thickness according to the Global Osteitis Scoring Scale (GOSS) by Georgalas and others, which is based on bone thickness measurement, but this indicator does not always reflect the degree of destruction. [3].

2. Purposes, subjects and methods:

2.1 Purpose - to determine the physiological age variability of the posterior and inferior walls of the frontal sinus and to compare it with those in chronic purulent-polypous frontal sinusitis. 


\subsection{Subjects \& Methods}

The study was carried out within the framework of the planned comprehensive research carried out at Kharkiv National Medical University on the topic "Morphological features of organs and systems of the human body at the stage of ontogenesis", state registration number 0144 U004149.

Spiral computed tomography (SCT) is one of the most informative non-invasive intravital method for examination of paranasal sinuses [8]. The study involved 40 male patients (to exclude the impact of factors occurring during menopause, women were excluded from this study). The study implied evaluation of SCT findings of 10 patients aged $30-40$ years and 10 patients aged $75-85$ years who underwent this examination in connection with a disorder not related to ENT organs (a tomography was performed to determine the presence of an unconfirmed stroke). The study also included 20 patients with chronic purulentpolypous frontal sinusitis, who underwent examination in accordance with the order of the Ministry of Health of Ukraine No. 181 as of 24 March 2009 "On approval of medical treatment protocols in the field of otorhinolaryngology". Ten of these patients were aged 30-40 years and ten were aged $75-85$ years. The Hounsfield scale [6] showed that the density of the posterior wall was potentially dangerous for the development of intracranial complications [4], and the inferior wall of the frontal sinus was dangerous for the development of intraorbital complications [9]. The obtained digital data were statistically processed using the Student-Fisher method, the mean value for each variation series $(\mathrm{X})$, the mean-square deviation, and the mean error $(\mathrm{m})$ were determined. Statistical processing was performed on a personal computer using Microsoft Office Excel 2010 (US). Statistically significant results were considered $\mathrm{p}<0.05$.

Conflict of interests. There is no conflict of interests.

\section{Results and discussion}

The results of calculations are presented in tables 1-4.
Physiological mean density of the posterior wall of the frontal sinus was calculated as follows: in the group of people aged 30-40 it was 191.5.1 $\pm 11.6 \mathrm{Hu}$, and in the group aged $75-85-169.1 \pm$ $16.8 \mathrm{Hu}$ in the inferior wall and $176.6 .1 \pm 21 \mathrm{Hu}$ and $164 \pm 21 \mathrm{Hu}$, respectively, in the region of the posterior wall (table 1, 3). The inferior wall density was $165 \pm 18.8 \mathrm{Hu}$ and $137.6 \pm 14.4 \mathrm{Hu}$ in accordance with the above order. The study showed that the density of bone tissue significantly $(p<0.05)$ decreased with age.

In chronic purulent-polypous sinusitis, the density was $120.1 \pm 8.3 \mathrm{Hu}$ and $101.4 \pm 8.3 \mathrm{Hu}$ in the inferior wall and $162.1 \pm 24 \mathrm{Hu}$ and $127.4 \pm$ $15.4 \mathrm{Hu}$ in the posterior wall in accordance with the above order.

Calculation and comparison of densitometric indices of different groups under investigation showed that the density of bone tissue significantly depended on age $(p<0.05)$. It decreased with age both in physiological conditions $p=0.00035$ and $p=0.0016$ in the region of the inferior and posterior walls, respectively, and in conditions of chronic purulent-polypous maxillary sinusitis $p=0.002$ and $p=0.0016$ according to the specified order.

Physiological density of the inferior and posterior walls of the frontal sinus in was calculated two different age groups. The density of the posterior wall was found to be greater in the group of people aged 75-85. Moreover, physiological density decreased not only with age, but also in chronic inflammation. However, at young age, these changes were more pronounced, by $26 \%$ as opposed to the age group of $75-85$ years, where it decreased by only $9 \%$. Such a more severe response is likely to be due to the increased tension of the immune response to the inflammatory process and the uniqueness of the immune response to the pathological process in the elderly [10].

Thus, age has a significant meaning not only in the course of chronic rhinosinusitis, but also in the physiological density of bone tissue in general and frontal sinus in particular. Older people undergo rearrangements in the structure and

Table 1

Physiological density of bone tissue of the inferior wall of the frontal sinus

\begin{tabular}{|c|c|c|c|c|c|c|c|c|c|c|c|c|}
\hline $\begin{array}{c}\text { Age } \\
\text { (years) }\end{array}$ & 1 & 2 & 3 & 4 & 5 & 6 & 7 & 8 & 9 & 10 & $x$ & $M$ \\
\hline $30-40$ & 195 & 183 & 195 & 178 & 197 & 215 & 172 & 194 & 186 & 200 & 191,5 & 11,6 \\
\hline $75-85$ & 142 & 173 & 179 & 157 & 198 & 182 & 154 & 182 & 175 & 149 & 169,1 & 16,8 \\
\hline
\end{tabular}


Table 2

Density of the inferior wall of the frontal sinus in chronic purulent - polypous sinusitis

\begin{tabular}{|c|c|c|c|c|c|c|c|c|c|c|c|c|}
\hline $\begin{array}{c}\text { Age } \\
\text { (years) }\end{array}$ & 1 & 2 & 3 & 4 & 5 & 6 & 7 & 8 & 9 & 10 & $x$ & $M$ \\
\hline $75-85$ & 105 & 93 & 98 & 89 & 94 & 108 & 109 & 107 & 108 & 103 & 101,4 & 6,95 \\
\hline $30-40$ & 116 & 113 & 124 & 128 & 121 & 139 & 112 & 117 & 115 & 116 & 120,1 & 8,3 \\
\hline
\end{tabular}

Physiological density of the bone tissue of the posterior wall of the frontal sinus

\begin{tabular}{|c|c|c|c|c|c|c|c|c|c|c|c|c|}
\hline $\begin{array}{c}\text { Age } \\
\text { (years) }\end{array}$ & 1 & 2 & 3 & 4 & 5 & 6 & 7 & 8 & 9 & 10 & $x$ & $M$ \\
\hline $30-40$ & 190 & 140 & 210 & 165 & 168 & 196 & 178 & 167 & 152 & 200 & 176,6 & 21 \\
\hline $75-85$ & 168 & 154 & 216 & 141 & 173 & 155 & 157 & 151 & 151 & 174 & 164 & 21 \\
\hline
\end{tabular}

Table 4

Density of the posterior wall of the frontal sinus in chronic purulent - polypous sinusitis

\begin{tabular}{|c|c|c|c|c|c|c|c|c|c|c|c|c|}
\hline $\begin{array}{c}\text { Age } \\
\text { (years) }\end{array}$ & 1 & 2 & 3 & 4 & 5 & 6 & 7 & 8 & 9 & 10 & $x$ & $M$ \\
\hline $30-40$ & 172 & 165 & 159 & 178 & 163 & 140 & 154 & 135 & 178 & 177 & 162,1 & 24 \\
\hline $75-85$ & 135 & 158 & 93 & 138 & 145 & 107 & 118 & 137 & 154 & 89 & 127,4 & 15,4 \\
\hline
\end{tabular}

microarchitectural structure of the bones due to the shortage of steroid hormones in this age category [11], which has been repeatedly proven for the femur in elderly. Our study allows us to assume the correctness of this statement for bone tissue.

Thus, elderly patients should be treated with extreme caution, since the density of bone tissue of the frontal sinus is physiologically lower, although its reduction under the action of purulentpolypous process is less severe than in the group of younger patients. It has been shown that the inferior wall density in patients aged $75-85$ is reduced more than that of the posterior wall, suggesting higher probability of intraorbital than intracranial complications in this group of patients.
Conclusions. Thus, the following conclusions can be drawn from the research:

1. Physiological density of the posterior wall is more than that of the inferior in people aged 75-85.

2. The density of the inferior and posterior walls of the frontal sinus significantly $(\mathrm{p}<0.05)$ varies with age.

3. The density of both inferior and posterior walls, equally decreases with age by $9.9 \%$ and $6.4 \%$ respectively.

4. Under the influence of pathological process, the posterior wall density is more stable in the group of people aged $75-85$ and is reduced only by $9 \%$, whereas in patients aged $30-40$ by $26 \%$.

\section{References:}

1. Adouly T, Adnane C, Khallouk A, et al. (2017). Moroccan adaptation and validation of the rhinosinusitis quality-oflife survey. Eur Arch Otorhinolaryngology, 274(3):1507-1513.

2. Carr T.F.(2016). Complications of sinusitis. Am J Rhinol Allergy, Vol. 30 (4). - P. 241-245.

3. Dong Y,Zhou B, Niu YT, Wang ZC (2011). [CT evaluation of bone remodeling in rabbit models with rhinosinusitis]. [Article in Chinese]. Zhonghua Er Bi Yan Hou Tou Jing Wai Ke Za Zhi., 46(10):848-53.

4. Freeman JL, Winston KR. (2015). Breach of Posterior Wall of Frontal Sinus: Management with Preservation of the Sinus. World Neurosurg,.83(6):1080-9. doi: 10.1016/j. Dec 18..12.023. wneu.2014.

5. Halawi AM, Smith SS, Chandra RK. (2013). Chronic rhinosinusitis: epidemiology and cost. Allergy Asthma Proc, 34(4):328-334

6. Hofer M. CT Teaching Manual - A Systematic Approach to CT Reading, $2^{\text {nd }}$ Ed.P. 20.

7. Renteria AE, Mfuna Endam L, Desrosiers M.Do (2017). Aging Factors Influence the Clinical Presentation and Management of Chronic Rhinosinusitis? Otolaryngol Head Neck Surg., 156(4):598605. doi: 10.1177/0194599817691258.

8. Schaafs LA, Pfeil J, K?hlitz T, Hamm B, Niehues SM. (2018). Low-dose computed tomography of the paranasal sinuses: performance of two different iterative reconstruction algorithms Radiat Prot Dosimetry., Aug 25. doi: 10.1093/rpd/ncy153]. 
9. Shumway CL., Wade M. (2018). Anatomy Head and Neck, Orbit Bones StatPearls [Internet]. Treasure Island (FL): StatPearls Publishing; Sep 25.

10.Stanojcic M, Chen P, Xiu F, Jeschke MG. (2016). Impaired Immune Response in Elderly Burn Patients: New Insights Into the Immune-senescence Phenotype. Ann Surg., 264(1):195-202. doi: 10.1097/ SLA.0000000000001408].

11. Torremade-Barreda J, Rodriguez-Tolra J, Roman-Romera I, Padro-Miquel A, Rius-Moreno J, Franco-Miranda E. (2013). [Testosterone-deficiency as a risk factor for hip fracture in eldery men]. [Article in Spanish] Actas Urol Esp., 37(3):142-6. doi: 10.1016/j.acuro.2012.06.009. Epub 2012 Dec 13.

12.Kucuksezer UC., Ozdemir C., Akdis M., Akdis CA. (2018). Chronic rhinosinusitis: pathogenesis, therapy options, and more. Expert Opinion on Pharmacotherapy. 2018 Nov;19(16):1805-1815. doi: 10.1080/14656566.2018.1527904. Epub 2018 Oct 20.

13. Volkov AG, Stagnieva IV. (2012). Ostryj i hronicheskij frontit: tekushhee sostojanie problemy [Acute and chronic frontitis: the current view of the problemi]. Vestn Otorinolaringol., (6):98-102.

Received: 23-Jan-2019

Accepted: 17-Mar-2019 